\title{
THE ISSUE OF DOCUMENTATION OF HARDLY ACCESSIBLE HISTORICAL MONUMENTS BY USING OF PHOTOGRAMMETRY AND LASER SCANNER TECHNIQUES
}

\author{
Karol BARTOŠ ${ }^{1}$, Katarína PUKANSKÁ ${ }^{1}$, Juraj GAJDOŠÍK ${ }^{2}$ and Miroslav KRAJŇÁK ${ }^{1}$ \\ ${ }^{1}$ Technical University Košice, Faculty of Mining, Ecology, Process Control and Geotechnology, \\ Institute of Geodesy and Geographical Information Systems, Košice, Slovakia \\ Karol.Bartos@tuke.sk, Katarina.Pukanska@tuke.sk, Miroslav.Krajnak@tuke.sk \\ ${ }^{2}$ GEOSPOL, s.r.o., Urbánkova 64, Košice, Slovakia
}

Keywords: Photogrammetry, 3D laser scanning, Cultural Heritage, Slanec castle

\begin{abstract}
This article deals with issues of measuring hardly accessible historical monuments on the example of the Slanec castle, Slovakia. In the first phase the convergence case of close-range photogrammetry was applied using digital camera Pentax K10D. Subsequently was created its 3D model in the PhotoModeler Scanner software. Special attention was paid to shape of ground, surroundings and characteristic of object of interest about choice of the right method and technique of making digital images. Processing of images was made with the highest possible accuracy with respect to the used method and apparatus. As a result of processing, the exact spatial model was made, which was exported to different formats. Also digital photo-plan with real photo textures and vector drawings was made. In the next phase the whole object of castle was measured with the laser scanner Leica ScanStation C10 and the final point cloud was processed in the best available software. The results obtained by both methods were compared in comparable digital formats with respect to the positional accuracy of final models. In the final phase is planned to obtain images appropriate for convergence case of photogrammetry using digital camera placed on a carrier on the MikroKopter HexaKopter controlled from the ground. Then the final comparison and further analysis of all acquired models can be made.
\end{abstract}

\section{INTRODUCTION}

Every ruin is a natural part of each cultural landscape, where creative human activities took place at least for a while. Ruins can be seen either as a dilapidated building to be re-build perhaps even removed, or as a component which gives an inconvertible character to the landscape; highlights the picturesqueness and materializes its history. Their life span is not eternal; it's limited, although we can prolong it by adequate preservation. Ruins of historical monuments are mainly represented by the ruins of medieval castles in Slovakia; they dominate the cliffs of Carpathian Mountains. Many of today's ruins were once busy and comely buildings in which were happening lots of happy or tragic stories of their dwellers. Nowadays, we can actually reconstruct these ruins - we have technical opportunities, but it's appropriate just in some cases. However, we can also preserve and maintain them; and thereby vitalize them. Not like erstwhile, but today's. Do it in such a way that we can stay for a while, meditate and look into ourselves to see into the raison d'être. In a beautiful surroundings of a substantial time witnesses [1]. The objective of this paper is a comparison of laser scanning technology and digital photogrammetry for the documentation of historical monuments which are situated in a hardly accessible terrain with limited options of movement and selection of camera/scanner stations on the example of the Slanec castle, Slovakia.

\section{THE SLANEC CASTLE - HISTORY AND PRESENT}

The Slanec castle is a gothic castle from the 13th century, destroyed and ruined in 1679. One three floor tower and several walls have been preserved; broken arch of a lancet window stands out architecturally. The ground plan of the castle is a simple rectangular shape, trapezoidal narrowed on the northwest side (Fig. 1a). There is a four floor high rounded donjon (Fig. 1b). Beside the tower is the wall of the Gothic palace (Fig. 1b), with preserved gothic window of the chapel and beautiful Gothic arch beams. [2,3] 

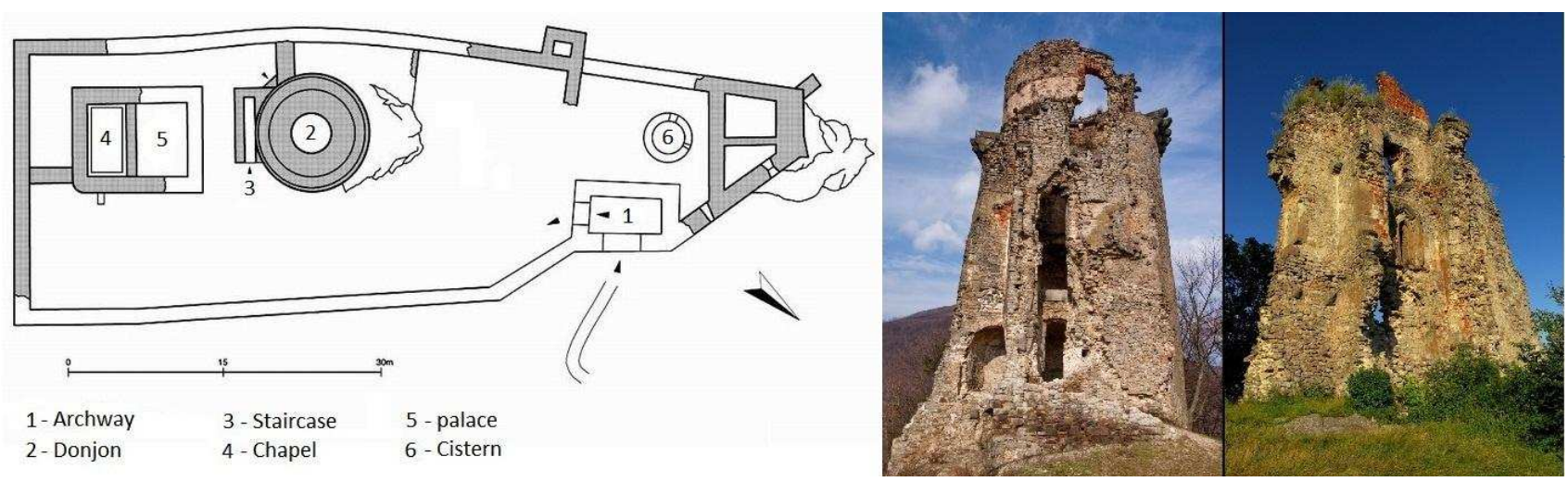

Figure 1: a) Ground plan of the Slanec castle and b) Details of the donjon and remains of the wall

\section{RECONNAISSANCE OF THE LOCALITY}

The whole object of the castle ruins is located in hardly accessible terrain on a conical hill of volcanic origin. It's surrounded by steep slopes overgrown with briery bushes with very limited possibilities of movement on the southern and western side. There is relatively dense beech wood obscuring the entire castle ruins on the north and east side. In addition, part of the ruins is buried and overgrown with vegetation in a great measure. All these conditions make it difficult to approach, surveying the castle ruins, handling with instrumentation and they degrade the results measurement. Therefore a combination of multiple methods for measuring individual parts was chosen and in the end comparing of particular results with respect to their accuracy.

The measuring was divided into three consecutive stages:

1. Close-range photogrammetry with convergent images acquired from the ground

2. Terrestrial laser scanning

3. Aerial close-range photogrammetry with convergent images acquired with digital camera placed on a carrier on the MikroKopter HexaKopter controlled from the ground

\section{PHOTOGRAMMETRIC MEASUREMENT OF RECENT SITUATION}

\subsection{Imaging}

The imaging was executed for appropriate and accessible parts of the castle, i.e. wall of the Gothic palace, using convergent imaging with general orientation of image axis. The measurement of the tower (donjon) using this method was evaluated as inappropriate or even impossible due to its shape and location.

For measurement of recent situation were used points signalized by:

- naturally: with measurement accuracy of 3 pix (corners, edges, intersections),

- artificially: with manual measurement accuracy of $0,5-1$ pix.

Major part of points was signalised naturally due to the dangerous installation of measuring marks straight on the wall. Artificially signalised points, used as a ground control points, were represented by 10 retro-reflective targets placed on the wall with the help of a professional rock climber. In order to situate the final model into the national coordinate system JTSK (Datum of Uniform Trigonometric Cadastral Network), the real world coordinates of these points were defined by electronic tachymeter Leica TCR 305. Surveying with Leica TCR 305 was performed from 3 fixed points, which were defined by the RTK method of the GPS technology. JTSK national coordinate system was used for the purpose of comparison with results from other stages.

\subsection{Accuracy analysis}

Total a priori accuracy of the final model can be defined as follows:

$$
m_{p}^{2}=\sigma_{p}^{2}+\sigma_{\varepsilon}^{2}
$$

where:

- $\sigma_{\varepsilon}$ is the external accuracy given by the standard positional error of ground control points (10 retro targets) 
- $\sigma_{\mathrm{p}}$ is the internal accuracy estimated by the formula:

$$
\sigma_{p}=\frac{q \cdot \sigma_{S} \cdot m_{S}}{\sqrt{k}}
$$

where:

- $\sigma_{\mathrm{S}}$ is the standard error of coordinates image,

- $\mathrm{m}_{\mathrm{S}}$ is the averaged image scale number,

- $\mathrm{q}$ is the configuration factor; for convergent photogrammetry reaches values $0,5-0,7$;

- and $\mathrm{k}$ is the average number of images taken from one camera position.

Due to different distances from the camera stations to the wall, which affects the image scale number, two estimations of the total theoretical a priori standard positional error were determined. One for the lower parts and one for the upper parts of the wall:

$$
\sigma_{P_{S}}=31,78 \mathrm{~mm} \quad \sigma_{P_{V}}=39,00 \mathrm{~mm}
$$

\subsection{Technology and software}

GPS measurement of 3 fixed initial points 5001, 5002 and 5003 (fig. 5) was performed with Leica GPS900 CS. Because of the use of RTK surveying method instead of static GPS survey, the coordinates of these 3 points were determined by averaging of the values of 5 measurements for relatively better accuracy of final coordinates. Horizontal accuracy of the Leica GPS900 CS is $10 \mathrm{~mm}+1 \mathrm{ppm}$ and vertical $20 \mathrm{~mm}+1 \mathrm{ppm}$. Positional measurement of 10 retro-reflective targets was realized in the national coordinate system JTSK using electronic tachymeter Leica TCR 305. Standard angular deviation of the instrument is $5^{\mathrm{cc}}$ according to DIN 18723 / ISO 12857. Accuracy of the infrared distance measurement is $2 \mathrm{~mm} \pm 2 \mathrm{ppm}$. Digital SLR Pentax K10D with Sigma 17-70 mm Lens (fig. 2) were used to acquire images. All images were acquired with a focal distance of $17 \mathrm{~mm}$. Camera calibration for given focal length was performed before by using of square calibration grid.
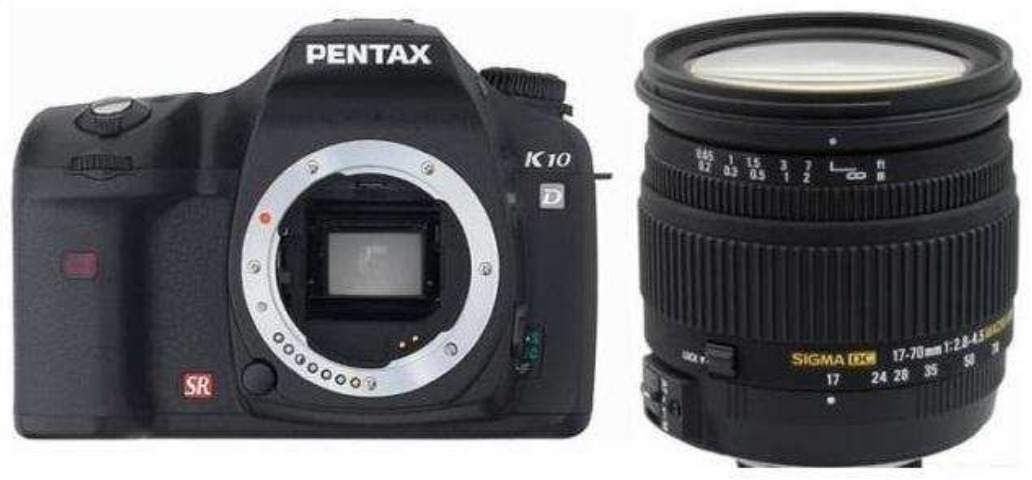

\begin{tabular}{|l|l|l|l|}
\hline Image format & \multicolumn{2}{l|}{$\mathrm{PEG}, \mathrm{RAW}$} \\
\hline Number of pixels & 10200000 \\
\hline Resolution & $3872 \times 2592$ pixels \\
\hline Focal distance & $17-70 \mathrm{~mm}$ \\
\hline Size of the CCD senzor & $23,5 \times 15,7 \mathrm{~mm}$ \\
\hline \multirow{2}{*}{ Distortion } & $\begin{array}{c}\text { Radial } \\
\boldsymbol{K}_{1}, \boldsymbol{K}_{2}\end{array}$ & $5,094 \mathrm{e}^{-4}$ & $-9,880 \mathrm{e}^{-7}$ \\
\cline { 2 - 4 } & $\begin{array}{c}\text { Decentring } \\
\boldsymbol{P}_{1}, \boldsymbol{P}_{2}\end{array}$ & $-2,368 \mathrm{e}^{-5}$ & $-1,304 \mathrm{e}^{-5}$ \\
\hline
\end{tabular}

Figure 2: Pentax K10D with Sigma 17-70 mm lens and its technical specification

Camera calibration as well as evaluation of all images of the castle wall was performed in the PhotoModeler Scanner software. PhotoModeler Scanner solves calculations of justified components of the exterior orientation on the basis of perspective transformation. Spatial coordinates of joining and determining points are calculated by spatial intersection based on known parameters of exterior orientation. Calculation of the spatial coordinates of projection centers, ground control points and observation points is realized by bundle adjustment of perspective rays in the reference coordinate system.

\subsection{Visualization of the 3D model}

Before processing all of images were idealized on the basis of calibration parameters in order to remove lens distortion. The ideal central projection, which unlike the real distorted projection of lens doesn't deform lines to curves, was achieved by using the idealization function. Idealization of images enables to achieve high quality textures without background showing-through all over the object. The final set of $3 \mathrm{D}$ points was created by successive orientation of prepared images and then by referencing identical points. It was necessary to assign the scale and rotation in space to this set of points by defining the XYZ coordinates of 3 points - retro-reflective targets. Total of 1639 points on 50 images have been used to create the final model with average number of 189 points per one image and with average intersection angle of $73^{\circ}$. Subsequently the wireframe model of castle wall was made by joining individual points. 
Individual surfaces were assigned to the each area bordered by lines and textures from images were loaded for these surfaces. Lastly the final 3D vector model with real photo textures was created after loading and processing of all textures (fig. 3). The final spatial accuracy of points ranged from $0,4 \mathrm{~cm}$ in direction of Z-axis to $2,97 \mathrm{~cm}$ again in the direction of $Z$-axis. The value of average length of the RMS vector was $2,13 \mathrm{~cm}$ and the total RMS reached value of 2,506 pixel. The accuracy of the final model was controlled directly in the Photomodeler Scanner software by means of confidence ellipses (Fig. 4b). The final model was exported into the interchangeable .DXF format for further comparison.
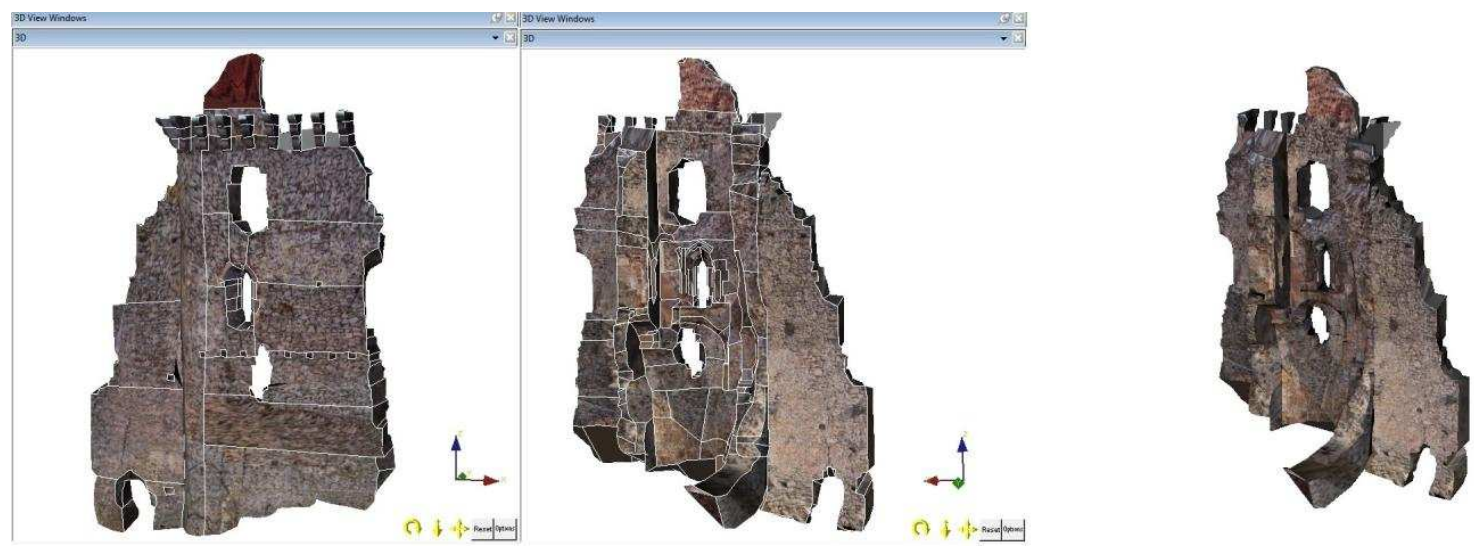

Figure 3: The 3D vector model with displayed textures and an axonometric view of the wall

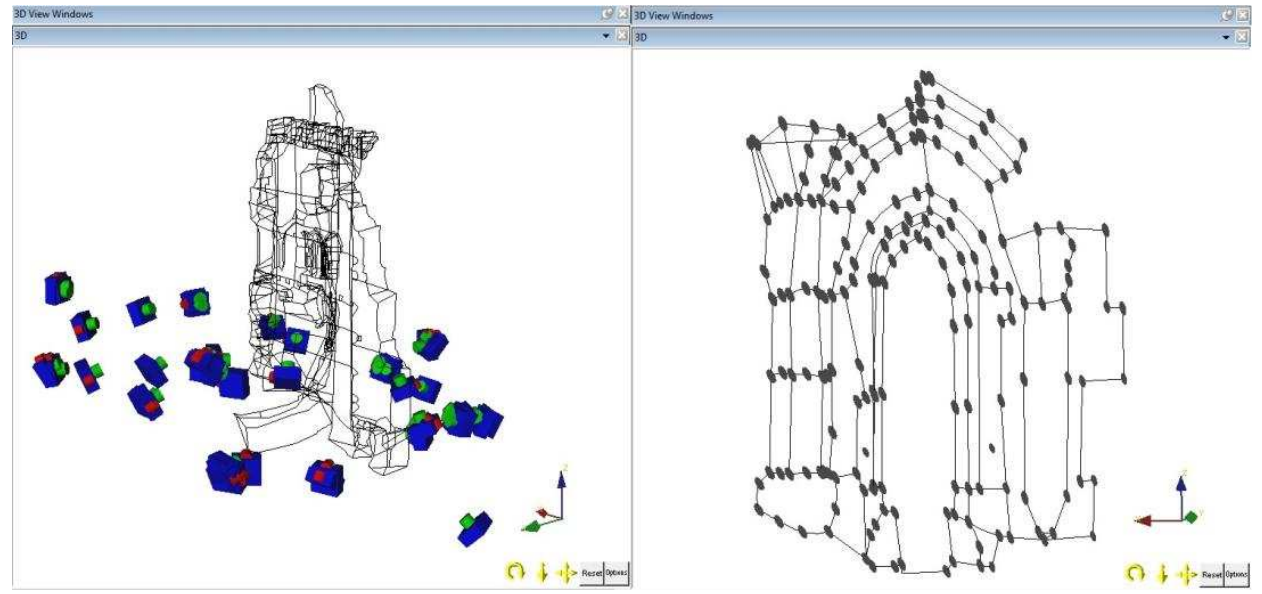

Figure 4: a) The deployment of camera stations, b) Confidence ellipses displayed for the gothic window

\section{LASER SCANNING}

\subsection{The scanning of the Slanec castle}

The scanning was carried out for the whole object of the castle, including buried and overgrown parts, in the coordinate system JTSK. Following types of data were recorded during laser scanning:

- range $\mathbf{r}$,

- horizontal direction $\varphi$,

- vertical angle $\theta$,

- Intensity of the reflected laser signal at each point.

Three scan stations over a known point - determined by the RTK method of the GPS technology (as described in chap. 4.3); and three temporary stations (5101, 5102 and 5103) (fig. 5) which were surveyed by the method of oriented distance by using of the laser scanner; were used to scan the whole object. A direct georeferencing was applied to transform the registered point cloud of the whole object into our chosen - national coordinate system. I.e. the scanner was set up over a known point (and its height over the point measured), centred, levelled and oriented towards another known target (backsight), like a total station. The position and orientation information as well as the instrument height was entered into the scanner software before the scanning. 


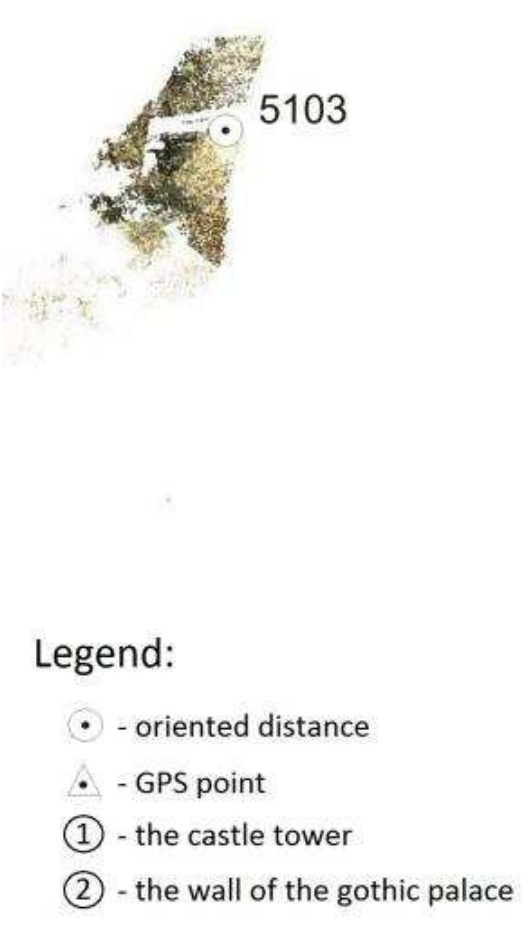

(1)

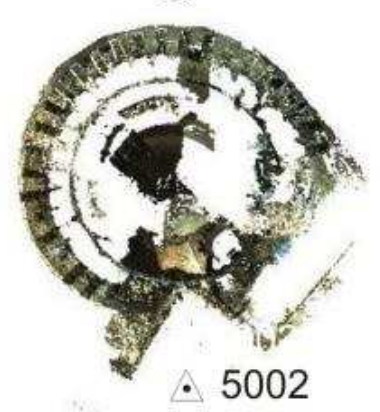

5001

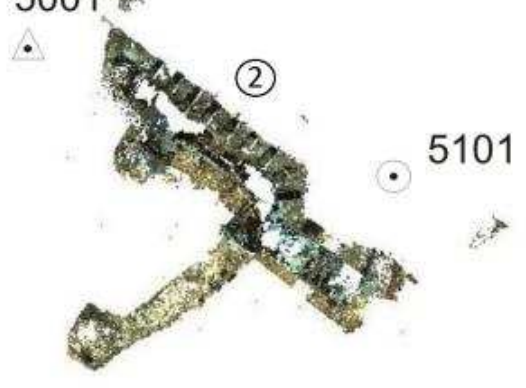

5003

Figure 5: General map of the final scan from above

The accuracy of direct georeferencing depends on:

- The accuracy of the scanner centering, leveling and backsighting and measuring the instrument height;

- The accuracy of the survey control, i.e. the control points on which the scanner (and possibly the backsight target) is placed.[3]

\begin{tabular}{|c|c|c|c|c|c|}
\hline Station & Orientation & $\Delta \mathrm{X}[\mathrm{mm}]$ & $\Delta \mathrm{Y}[\mathrm{mm}]$ & $\Delta \mathrm{Z}[\mathrm{mm}]$ & $\Delta \mathrm{d}[\mathrm{mm}]$ \\
\hline 5003 & 5001 & -14 & 2 & -16 & -14 \\
\hline 5001 & 5003 & 17 & -2 & 17 & -17 \\
\hline 5101 & 5001 & 0 & 0 & 3 & 0 \\
\hline 5002 & 5001 & -14 & -12 & -14 & -15 \\
\hline 5102 & 5001 & -7 & 2 & -3 & 7 \\
\hline 5101 & 5102 & 0 & 1 & 0 & -1 \\
\hline
\end{tabular}

Table 1 : Registration accuracy of particular scans from 6 scan stations

The final point cloud was processed by the use of Leica Cyclone 7.0 software (fig. 6). 


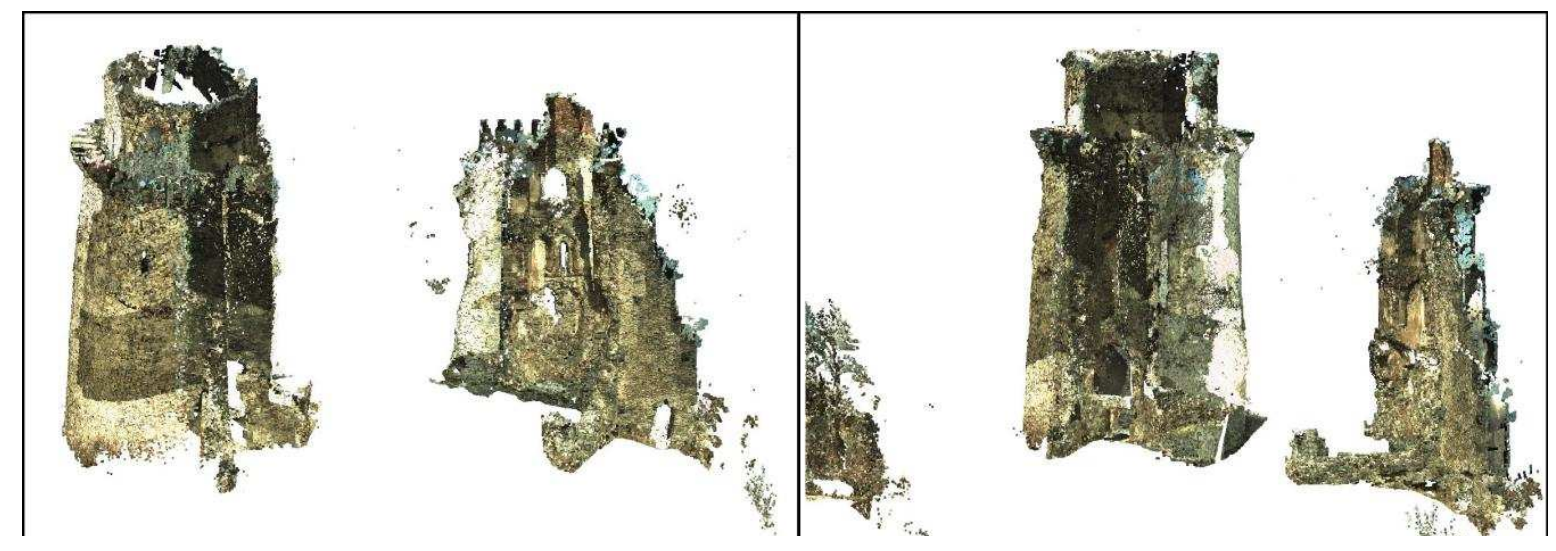

Figure 6: Southern and eastern isometric view of the final scan

\subsection{Technology and software}

The laser scanning was performed by the laser scanner Leica ScanStation C10.

The orientation on each of the stations was realized through the centred and levelled Leica HDS 6" circular tilt \& turn target.

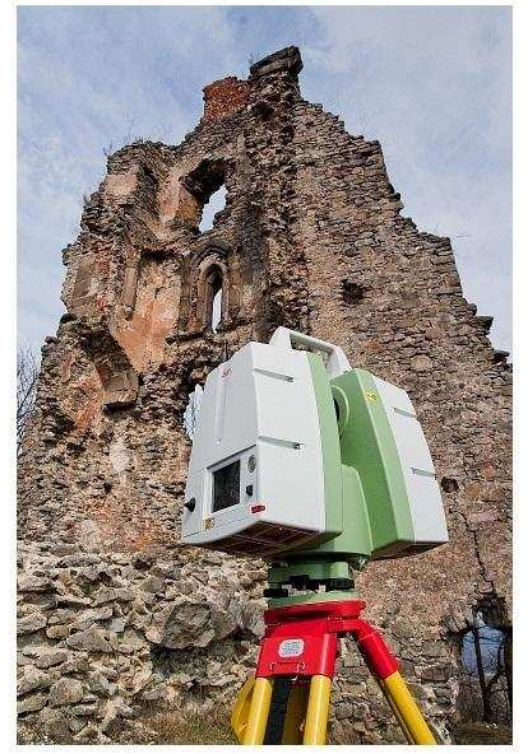

\begin{tabular}{|c|c|}
\hline \multicolumn{2}{|c|}{ Technical specification of Leica ScanStation C10 } \\
\hline Accuracy of single measurement & $6 \mathrm{~mm} / 4 \mathrm{~mm}$ \\
\hline Position/ Distance & $60 \mu \mathrm{rad}\left(12^{\prime \prime}\right)$ \\
\hline horizontal angle & $60 \mu \mathrm{rad}\left(12^{\prime \prime}\right)$ \\
\hline vertical angle & $2 \mathrm{~mm}$ \\
\hline Modeled surface precision & $2 \mathrm{~mm}$ (std. deviation) \\
\hline \multirow{2}{*}{ Target acquisition } & $300 \mathrm{~m}(90 \%$ albedo) \\
\hline \multirow{2}{*}{ Range } & $134 \mathrm{~m}(18 \%$ albedo) \\
\hline Min. step of scanning & $<1$ mm \\
\hline Scan rate & 50000 points/sec, max instantaneous rate \\
\hline Lasser class & $3 \mathrm{R}$, green $(\lambda=532 \mathrm{~nm})$ \\
\hline Spot size & $0-50 \mathrm{~m} \approx 4,5 \mathrm{~mm}$ \\
\hline Field of view & \\
\hline vertical & $270^{\circ}$ (maximum) \\
\hline horizontal & $360^{\circ}$ (maximum) \\
\hline Aiming/Sighting & parallax-free, integrated zoom video \\
\hline \multirow{3}{*}{ Dual-axis compensator } & Selectable on/off \\
\cline { 2 - 2 } & resolution $1{ }^{\prime \prime}$ \\
\cline { 2 - 2 } & dynamic range $+/-5^{\circ}$ \\
\hline & accuracy $1,5^{\prime \prime}$ \\
\hline
\end{tabular}

Figure 7: a) Leica ScanStation C10 over a scan station, b) its technical specification

\subsection{Processing of the final point cloud}

The 3D model of the wall created on the basis of the close range photogrammetry (Chap. 4.4) and the point cloud of the whole castle were available after the second stage. Point cloud of the castle tower and point cloud of the Gothic palace wall were exported separately just for the purpose of this paper. Both of clouds were exported from the Leica Cyclone software into the .PTS format and opened through the Trimble RealWorks 6.5 software, respectively Leica Cyclone 7.0. Subsequently the point cloud of the wall was cleared of all unwanted points (branches, bushes, grass). Adjusted point cloud of the wall contained 7656813 points. Due to the large number of points and hence the impossibility of their processing using a desktop computer this cloud was resampled by means of spatial sampling with a distance of 20,00 $\mathrm{mm}$ between points. Final set of points consisted of 863183 points. Corresponding mesh model was generated from this point cloud. Afterwards it was edited and adjusted by removing peaks, refining and smoothing (fig. 8a). For the point cloud of the castle tower was considered to make a spatial model by using of the Leica Cyclone 7.0 software, to generate a final mesh, try to model all missing parts and finally to make horizontal cross sections. Unfortunately, due to the unexpected software problems and problems with importing a point cloud into the software till completion of this 
paper, generating of the final mesh failed. The point cloud was used to model main part of the tower for the purpose of horizontal cross sections only (fig 8b).
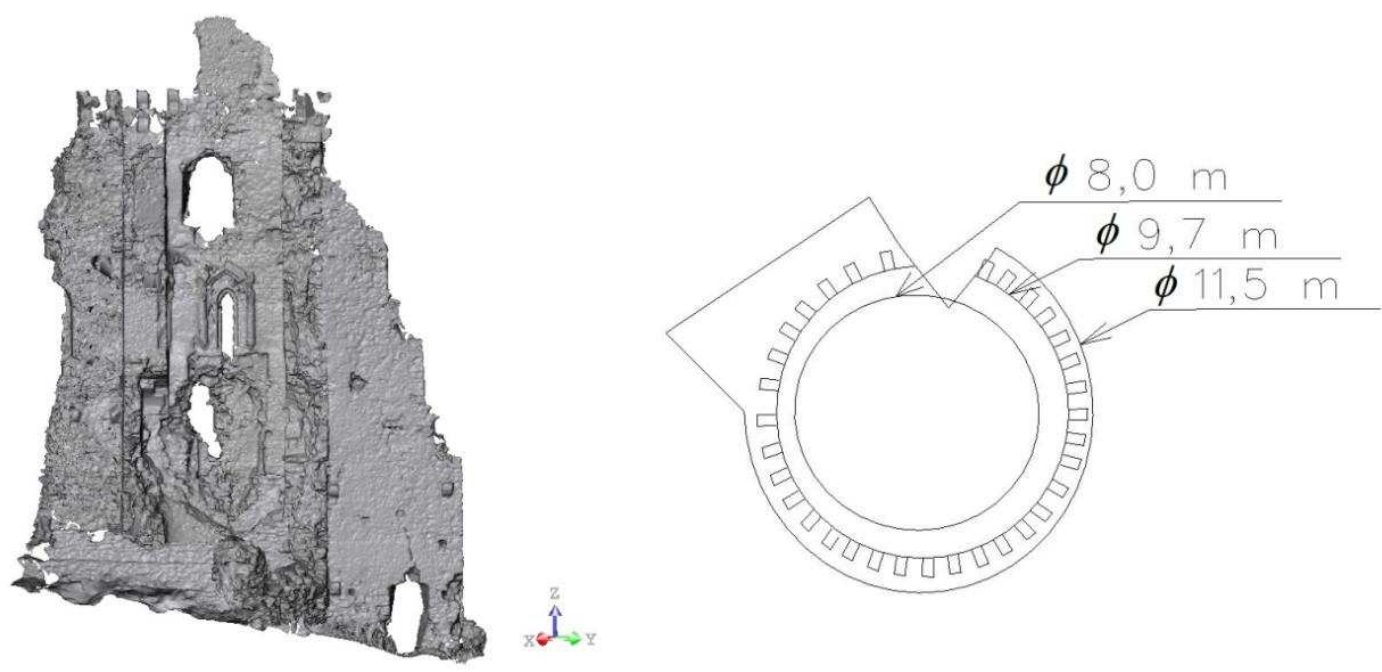

Figure 8: a) The final mesh of the palace wall, b) Cross sections of the castle tower

\section{RESULTS FROM THE FIRST AND SECOND STAGE}

Since both models of the wall, i.e. 3D model created on the basis of the close range photogrammetry and mesh from the laser scanning; were created and embedded into the same coordinate system JTSK on the basis of measurements performed from the same fixed points (5001, 5002 and 5003) determined by the GPS technology; they are at the same level of accuracy given by the accuracy of GPS determination of fixed point coordinates. Thus they can be opened simultaneously as a one project and compared together. For this purpose a cutting plane tool was used to generate a multiple horizontal slices with intervals of $200,00 \mathrm{~mm}$ and a thickness of $10,00 \mathrm{~mm}$. The resulting comparison of three cutting planes situated in three different levels - level of the terrain, level of the gothic window and the upper level with remnants of the cantilevers can be seen in the Fig. 8. The third stage, using the MikroKopter - HexaKopter, is beyond the scope of this paper mainly due to bad wind conditions during survey task (the castle hill is a relatively strong windy place). This stage is planned to take place as soon as possible to use its result for completing deficient places of the upper parts of models.

\section{CONCLUSION}

Photogrammetry together with laser scanning can be regarded as the predominant method of surveying historical objects. Advantages of photogrammetry compared to classical geodetic methods consist in: contactless measurements; a large saving of field works; high geometric and temporal resolution; constant visual contact with the measured object during the treatment process and possibility of projection photo-real textural information about measured surfaces into the result. It's important to take into account the specific conditions in the area of measured object while choosing photogrammetric methods, especially in terms of terrain, territory size, options in choices of viewpoints and undesirable objects which could be situated near the object and shade it. Lots of historical monuments in the form of medieval castles are situated in hardly accessible terrain. Afterwards, the problem of correct measurement and survey of these objects arises, either by use of photogrammetric or geodetic methods. Daresay combination of multiple photogrammetric methods using the latest technology may be the right way. Nowadays it is not just about the available technologies but especially about acquisition and investment of sufficient resources into the quality survey of historical monuments. Although Slovakia dispose of the newest technology, but unfortunately compared to the other countries where large attention is devoted to systematic photogrammetric documentation of historical monuments, Slovakia still has a lot to catch up. 

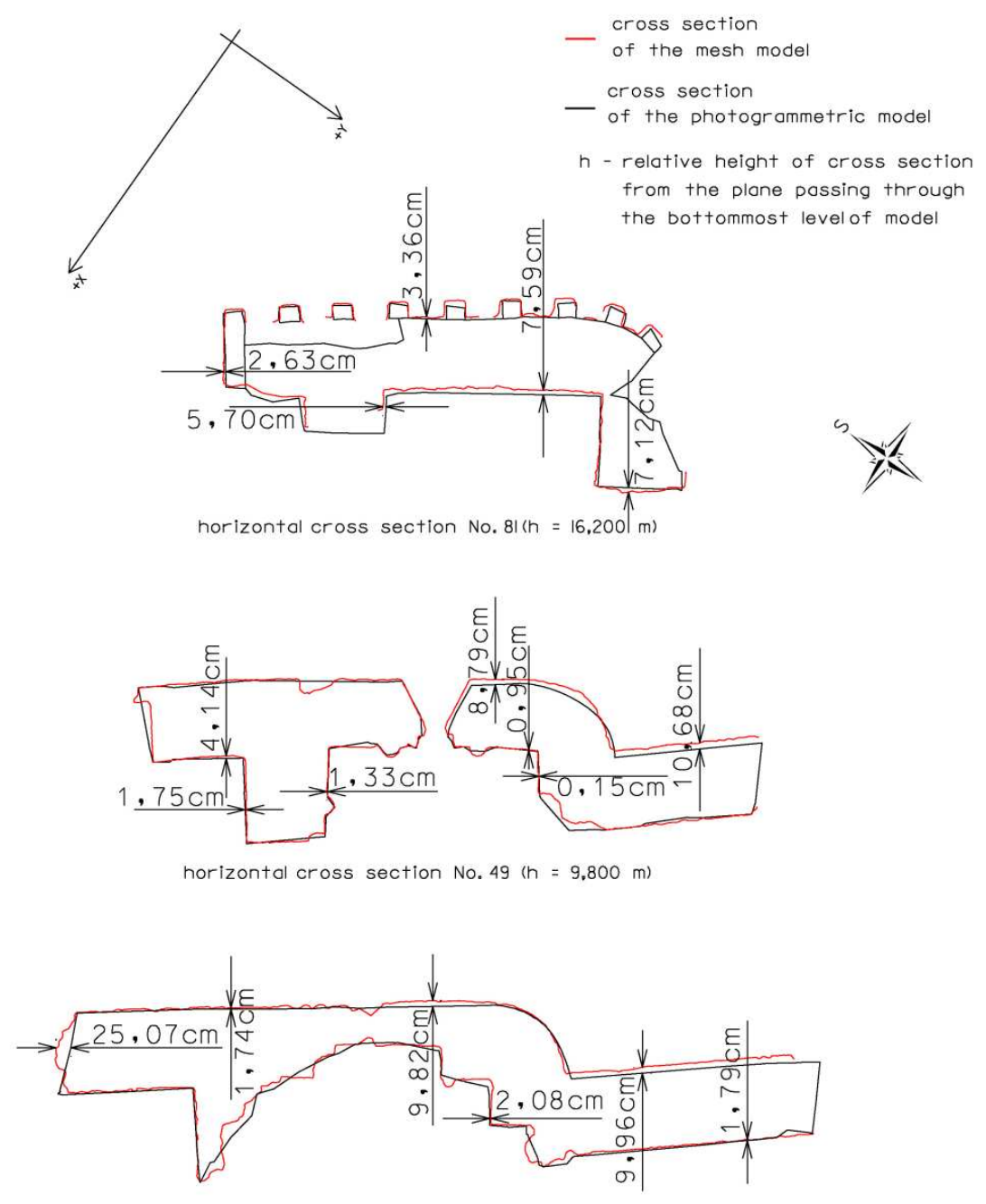

$1: 80$

horizontal cross section No. $29(h=5,800 \mathrm{~m})$

Figure 9: Comparison of horizontal cross sections through both models

\section{REFERENCES}

[1] The team of authors: Protection of ruins in a cultural country, Lietava, Association for Rescue of the Lietava Castle, 2006.

[2] Petro, F.: Attractions in history of the Slanec and surroundings, Obecný úrad Slanec

[3] Reshetyuk, Y.: Terrestrial laser scanning, Leipzig, VDM Verlag Dr. Muller Aktiengesellschaft \& Co. KG, 2009.

[4] FRAŠTIA, M.: Possibilities of using inexpensive digital cameras in applications of cloes-range photogrammetry, Slovak Journal of Civil Engineering, 2005/2, 20-28.

15] LUHMANN, T., ROBSON, S., KYLE, S., HARLEY, I.: Close range photogrammetry: principles, methods and applications, Caithness, Whittles Publishing, 2006.

[6] LABANT, S., KALATOVIČOVÁ, L., KUKUČKA, P., WEISS, E.: Precision of GNSS instruments by static method comparing in real time, Acta Montanistica Slovaca 14 (2009) 1, 55-61. 